\title{
Addressing the Challenges and Issues of Blood Donation via Ubiquitous Computing
}

\author{
Dian Pradhana Sugijarto\#, Nurhizam Safie*, Muriati Mukhtar ${ }^{*}$, Riza Sulaiman** \\ ${ }^{\#}$ Faculty of Information Science \& Technology, Universiti Kebangsaan Malaysia (UKM), Malaysia \\ *Research Center for Software Technology and Management, Universiti Kebangsaan Malaysia (UKM), Malaysia \\ **Institute Visual Informatic (IVI), Universiti Kebangsaan Malaysia (UKM), Malaysia \\ E-mail:dpsukm@gmail.com,nurhizam@ukm.edu.my,muriati@ukm.edu.my,riza@ukm.edu.my
}

\begin{abstract}
Blood is undeniably essential to save lives. The high demand for blood cannot compete with the amount collected through blood donation. In order to cater to the issue, researchers tend to focus more on the donors' side. Meanwhile, the other party which is the blood bank continues to play its role to increase the blood supply. The blood bank processes blood in four stages: donation, screening, inventory and hospital pickup. This paper aims to address the challenges and issues in the local blood bank through ubiquitous computing, specifically at the blood donation stage. Blood donation is the most critical stage where the blood bank engages directly with the donors. The issues and challenges faced by the blood bank are uncovered by, interviews, field study and literature reviews. The proposed solution takes advantage of the ubiquitous computing concept that enables devices to communicate with each other seamlessly. With the advancement of mobile technology, smartphones become the closest of any devices to achieve ubiquitous computing. Communication technologies like Near Field Communication and Wi-Fi aid the interaction between the user and the system which are expected to solve the challenges and issues of blood donation.
\end{abstract}

Keywords - Blood Donation, Ubiquitous Computing, NFC, Challenges, Mobile

\section{INTRODUCTION}

Blood products are crucial for transfusion as each of the blood components is required for several purposes. Blood which is extracted directly from the donor is called whole blood. It can be separated into three blood components which are red blood cell, plasma and platelet [1], [2]. Red blood cell transfusion is mainly used for kidney failure and acute blood loss [3]. Plasma is commonly transfused to patients with severe liver disease [4] while platelet is usually used to treat patients with cancer [5].

The supply of blood product depends totally on the donors themselves. It has been reported that the number of donors has fluctuated where the demand for blood product is fairly irregular across the world [6]. Donors are of paramount importance as they are the sole source of supply. It must not be forgotten as well that the blood bank is as important as the donors as it helps to manage the blood product.

The blood bank processes blood in four stages: donation, screening, inventory and hospital pickup. Blood donation is where the donor's blood is extracted. Then, the blood goes through a screening process where blood is filtered for major viruses. Inventory stores blood components according to each respective condition. The last stage is the hospital pickup. This is where the products are collected to be delivered to hospitals.
Since the supply of blood depends on the donors, the blood donation process becomes extremely crucial. It must be noted that blood donation can have positive and negative effects on the donors.

In relation to the study above, this paper begins with presenting the data gathering method in Section II. Results of literature review and survey are presented in Section III which describe issues faced in general blood banks and specifically in the local blood bank. It is important to understand the issues as the research motivation to solve them via ubiquitous computing technologies. Section IV discusses the proposed solution which utilized the concept of ubiquitous computing using a smartphone. The proposed system is one which enables a smartphone as a personal device to bridge the communication between donors and the blood bank's system seamlessly.

\section{RESEARCH METHOD}

The first data gathering method used was literature review. The literature review is performed to understand the process of acquiring blood in a blood bank and to discover the issues.

Data were collected through a series of interview sessions with the blood bank's technicians and nurses at National Blood Centre (NBC). The reason of choosing NBC instead of other blood banks is because it operates solely on blood collection 
and inventory. With regards to this, NBC is clearly a standalone institution that is supported by the government and it has superior facilities than any other institutions in the country.

The interviewed respondents were a technician who works as one of the head of Information Technology departments and the nurses who work in various divisions such as registration, bleeding room and inventory. The nurses were interviewed during a close field observation. Field observations were conducted through a series of processes starting from blood donation, screening, inventory and then hospital pickup. A selfblood donation was also carried out to grasp the feeling of a donor in regards to hospitality, environment and the blood donation process itself.

The next phase of method used is through the comparison with literature review. The issues acquired from the first phase were compared with literature reviews. The focus of this phase is to determine and show if other blood banks were facing similar issues and also to discover any other available solutions.

The last phase is generating ideas by considering current technology. Through reading and discussing ideas during the interviews, a ubiquitous system was proposed.

\section{CHALLENGES AND ISSUES OF BLOOD BANKS}

According to World Health Organization (WHO), blood banks has several core components [8]:

- A specific unit that is assigned by ministry of health to coordinate, manage and monitor the blood system throughout the country.

- Advisory body that is able to assist ministry of health in formulating policy and plans, setting standards and advising on key issues.

- Blood transfusion services (BTS) involved in donor recruitment, blood and plasma collection, and the testing, processing, storage and distribution of blood and blood products.

- Hospital blood banks, clinical transfusion services and transfusion committees are responsible for the timely provision of compatible blood and its safe and appropriate use.

In terms of geographical distribution, normally, blood banks are divided based on the region. When blood bank structure is grouped according to its geographic region, it is called regional blood centres (RBC) [9]. In general, each RBC is responsible to keep the supply of blood in hospitals within the region. Blood products are delivered to hospitals on a regular basis in order to ensure that an adequate supply of the required blood products is available [10].

Either NBC or other blood banks have similar issues especially in blood donation as its core function. This section discussed the common issues faced by blood banks and followed by specific issues faced by NBC, a local national blood bank Malaysia. It is important to understand common issues as a ground knowledge on how to solve the issues using ubiquitous technology.

\section{A. Common Issues in Blood Donation}

Blood donation is one of the crucial and main task of a blood bank. However, most of blood donations are depended on voluntary donation which causes many issues.

The following are issues and problems regarding blood donation.

\section{1) Promoting a Blood Donation}

Discovering the best promotion strategy is always the main concern in voluntary blood donation [11]. Since it is a voluntary donation, it has to consider motivational and psychological factors of donor [12]. Bekkers and Wiepking [13] described eight mechanisms as the most important forces that drive charitable giving: (1) awareness of need; (2) solicitation; (3) costs and benefits; (4) altruism; (5) reputation; (6) psychological benefits; (7) values; (8) efficacy.

Bednall and Bove [14] concluded that donation behaviour can be indicated by forms of marketing communication, including direct marketing (i.e., face-to-face, telephone and mailed appeals to donate), mass-media advertising, and workplace blood drives. Bednall and Bove [14]'s study has shown that direct marketing was cited most often by repeat donors as a trigger for their donation behaviour, and less often by other donors. In contrast, advertising was mentioned most often by lapsed donors as a donation trigger, but infrequently by other types of donors.

\section{2) Complication during Blood Donation}

Fainting is one of complication that is commonly occurred in young donors aged between 16 and 17 years [15]. To cater this issue, Canada and UK have implemented a new criterion for donor acceptance based on estimated blood volume for fisttime donors aged 17-23 years [16]. The other prevention acts to reduce complication during blood donation is drinking cold water before donation and applied muscle tension during donation [16].

\section{3) Motivation Drivers for Donors}

Karacan et al. [17] identified the factors that would motivate donors to donate and develop new strategies to gain new donors and transforming first-time donors to repeaters (loyal donors). Altruism was reported as a common motivation for first blood donation. Request and need from families and relatives is also important motivation that drive people to donate. The authors did not find any significant statistical difference between motivation of long term and short term donors. The following are motivations that drive long term and short term donors: values and moral duty, positive feeling and self-esteem, selfbenefit and external reason.

Although there is no significant difference between long term and short term donor, women have different motivations than men. Mellström and Johannesson's [18] study shows that monetary compensation does not effect on men but it reduces $10 \%$ number of women. Women can also demotivated and stop donating if they experience practical problems and discomfort during donation [19].

\section{4) Post Donation}

Sojka and Sojka [20] studied post-effect after donation. The study resulted positive and negative effects. It was reported that female donors appeared to be more frequently affected by blood donation. Frequent positive effects include feeling of satisfaction, feeling of being more alert / more vigilant. Whereas, negative effects are tired, diminish physical capacity and vertigo / dizziness.

It is a common practice that after donation, donor's blood is tested to major viruses such as hepatitis B, hepatitis C, HIV/AIDS, syphilis and malaria [21]. But because of disclosure 
agreement between a blood bank and donors, donors do not know his result unless they contact the blood bank. Malaysia has better procedure in handling this issue. When a donor is infected with a tested disease, the blood bank contacts calls the donor for counselling [22]. However, Roshan and Rosline [22] reported that only few of them who respond and come for follow-up appointment.

\section{5) Donor Deferral}

When a donor wants to donate the blood to a blood bank, the donor must pass series of process. One of the process is to fill up a questionnaire regarding donor's current and medical history. Then, a doctor verifies the questionnaire's answer by interviewing the donor. This is to ensure that the blood is saved. In most cases, donor deferral means that a donor does not pass the requirement as a donor in which doctor has the authority to defer the donor.

Donor deferral can also be viewed from two other aspects: duration and who initiate the deferment. In term of duration, donor deferral is divided to two other categories: temporal and permanent deferral.

Temporal deferral means the donor has temporary medical condition that enable to donate such as low haemoglobin [23]. When a donor is indicated as temporary deferral, a doctor recommends certain amount of time for donors to be fully healed before the donors can donate their blood. Permanent deferral means that a donor has an untreated disease and it can spread by blood transfusion such as AIDS, hepatitis B and C [24]. Permanent deferral is discovered after screening test of donor's blood sample. That means, although donor has donated his blood, the blood will be discarded. Depends on the regulation, at some blood banks, the blood banks contact the donor if this case is happened [22]. At some other blood banks, donor does not know the result unless he contacts the blood bank himself.

The other the point of view of donor deferral is the person who initiates the deferral. Donor deferral can be initiated by the blood centre, which usually a doctor or by the donor himself through a self-deferral [25]. As mention earlier, when a donor does not pass certain criteria, a doctor has an authority to defer the donor. However, there are cases when donors defer themselves which usually happened to first time donor. Example of self-deferral causes are afraid of needle or changing mind.

Any type of deferrals cause blood bank loses potential donor. In Brazil, Gonçalez et al. [25] reported from three hospitals resulted $19 \%$ to $27 \%$ donor were deferred from 2007 to 2009 . Most of the cases were temporary deferral. The three most common deferral reasons were low haematocrit or haemoglobin, medical diagnoses, and higher-risk behaviour. Overall deferred candidates tend to be females and first-time donors. In Japan, between March 2010 to March 2011, Ngoma et al. [23] reported 14\% were deferred. Among the deferred, high proportion fall on people less than 20 years old, female and first time donor. Ngoma et al. [23] reported similar reason of deferring, which is low haemoglobin.

Donor deferral is inevitable, especially if the reason concerns about donor's medical condition. However, self-deferral can be reduced by several ways. Self-deferral is usually occurred on first timer donors, as they are more vulnerable to physiological attack. Anxiety is built up during the gap of waiting time. Vavic,
Pagliariccio, Bulajic, Dinić, \& Marinozzi's study [26] showed that giving fruit juice to first time donors before the donation process can reduce the anxiety.

In regard to chances of return, Bednall, Bove, Cheetham, \& Murray [27]'s study showed that donors with temporal deferral have higher chance to donate if they are requested to come back. This means that blood centre must record the number of days of the temporal deferral to be follow up.

This research does not intend to solve all the common issues in a blood bank. Nevertheless, the proposed ubiquitous computing system presented in Section V is hoped to contribute in solving some common and significant issues in a blood bank.

\section{B. Issues in National Blood Centre}

Malaysian Ministry of Health follows WHO's recommendation to have a national blood bank [8]. In Malaysia, National Blood Centre (NBC) is the official government blood bank which serves the needs of blood product for the whole country. Initially, NBC was a blood bank department as part of Kuala Lumpur General Hospital, but as the duty increased NBC was moved to a separate building with independent [28].

NBC has four core functions: donor recruitment and management, blood procurement and management, production and distribution of blood and blood products, and recipient management [29]. To cater the four functions, NBC forms several units [30]. Donor recruitment and transport unit has responsibility to get sufficient blood supply and provide vehicle for office use. Registration and record unit is responsible to provide registration counter and also storing and updating donors' record. Donor management unit is responsible to collect blood and apheresis product from blood donation held by NBC. Supply unit is responsible to store and supply whole blood and blood component to selected hospitals under Malaysian ministry of health, university hospitals, private hospitals and clinics [31].

NBC provides blood donation for whole blood and apheresis. Apheresis donation is only available at NBC's headquarter. Whereas, whole blood donation is available at NBC's headquarter and at any mobile donation sites [32].

The following are the issues faced by NBC throughout blood donation process especially issues related to technologies.

\section{1) Problem in Reading Identity Card's Chip}

The first process of blood donation is registration. During the registration process, candidates are required to show their identity card to the registrar while for foreigners, their passports would be required The Registrar scans the identity card that contains a chip using a card reader. One of the most common problems that occurred is where the card chip is unreadable because it is either smudged or scratched. When it is unreadable, the registrar has to key in the identification number manually.

\section{2) Limitation of Barcode Technology}

NBC uses a barcode system to track and label blood products. At the end of a typical process, each blood bag will consist of four labels: donator number, blood group, product code and expiration date [33]. Each of the labels has a barcode and a text version. NBC uses the label of component code which has similar meaning with product code [29]. The component code describes whether the blood product is whole blood, plasma platelet or any other component. 
Donors are also given a barcode that is attached to the donors' book record each time they make a blood donation. The barcode is attached after the donor has passed the registration process. The purpose of the barcode is for reference in case NBC has to check the donation status of the donor in the future.

The barcodes on a blood bag are used as identification. This process is not only applied at the blood bank but also in hospitals. Barcodes are scanned when the blood product is going to be stored and used in the hospital. Certain barcodes are needed to be scanned according to the transaction process [34]. Knels et al. [35] reported that to scan one barcode, it takes 1 to 2 seconds, which is considered inefficient. This is one of the reasons that 2-D barcode and Radio Frequency Identification (RFID) technology have been suggested to replace the current linear barcode [35]-[37].

\section{3) Efficiency of Contacting Donor Using SMS}

NBC keeps blood stock at the minimum quantity of 3000 blood bags. When the blood stock is low, NBC conducts more campaigns which involves up to four or five donation locations per day. A campaign means blood collection is done outside of the headquarters. Universities, shopping malls and hospital lobbies are the most common places for blood donation campaigns as they can attract more people to donate. NBC also contacts the donors via SMS. These donors are those that have fulfilled the minimum 60 days lapse after their last blood donation exercise. The SMS contains an invitation to donate blood at the nearest blood campaign sites. A specific remark like "Type A blood is needed" is sent if there is a great demand for that type of blood.

The advantage of sending messages via SMS is that it can be received with any kind of mobile phone. However, the main disadvantages of using SMS are the length of each message and its cost. Each SMS has a maximum of 160 characters which is inadequate. Besides that, SMS is very costly if it is sent to a large number of donors. NBC currently spends 10 cents per SMS.

\section{4) Risk of Data Exposure during Campaign}

When NBC conducts a blood donation campaign, registrars and doctors use laptops to modify and update the donor's data. The system that is used is the exact system used at NBC's headquarters. However, data is stored in the local drive. When the campaign is completed and the team returns to NBC, the data in the laptops is then transferred to NBC's server. Fig 1 describes the process.

Since data is stored locally, there are security and safety issues. Safety here means that the data can be lost, and damaged if the laptop is physically damaged. In terms of security, the data might be accessed by an unauthorized person.

\section{PROPOSED SOLUTION}

This section discusses solutions discovered from the literature review and the proposed ideas. The ideas have been discussed during the interview to verify their validity. The solutions must be implementable without making huge modifications to the current system and must not change the overall processes of blood donation or override the law, because they have been determined by the Ministry of Health $(\mathrm{MoH})$ [38]. Additionally, the solutions are expected to improve the engagement with donor, track progress of donor during the process and motivate donor during and after donation.

\section{A. System Requirements}

The following are the requirements to ensure the system works:

NFC on a smartphone. NFC is a short range wireless communication technology with high frequency [39]. It enables communication of devices within a 4-inch distance.

An application to be installed in the smartphone. The application acts as the client where it requests and receives information from the server. It also manages the NFC adapter of the smartphone.

$N F C$ readers on registration counter. NFC reader is a device to read data transmitted through the NFC. Usually, the NFC reader is connected to a computer to process the data.

NFC tag on each bed in the bleeding room. Each tag contains a string code which acts as an indication that blood extraction process is started.

$\mathrm{Wi}$-Fi network is provided. This is to ensure that the donor is able to connect to the internet to download the application and communicate with server.

The NFC is used during the initial and final stages of the blood donation process. In between the initial and final stages, the Wi-Fi connection handles the communication. One of the main points that makes NFC the suitable communication technology is that it does not to replace the current barcode system, rather, it works together with it [40]. The other advantage of NFC is that it is a close range communication which forces a user to bring the NFC device near to its reader that resemble a touch gesture [39]. The touch gesture is the reason NFC is chosen as one of technology that represents ubiquitous computing. It is a seamless communication allowing data to be transferred with simple interaction.

Wi-Fi connection is used when communication is needed without it being necessary for the user to perform the touch gesture. The short distance to use NFC can be either an advantage or disadvantage of the communication, depending on the situation. Assuming that the client needs to request and get up-to-date information during the whole process of blood donation, an internet connection will be needed. However, WiFi is not necessary if the user subscribes to a carrier's data plan.

\section{B. During Blood Donation Process}

The first process is registration. The donor is allowed to register by touching the phone to the NFC reader. The NFC enabled smartphone will have the ability to act as a card called card emulation [41]. When the device is on card emulation mode, it can be scanned using the NFC reader. The system then matches the ID read from the phone with the ID in NBC's database and displays necessary information on the registrar's screen. Meanwhile, new donors have to register manually and install the application on the phone. Implementing NFC also avoids the difficulty to scan chip on damaged identification cards caused by scratching or others.

The next process is either to check blood group or be interviewed by the doctor (depending on location of the donation). After each of the process is completed, the doctor input the information to a computer. Then, the server will send the status of the donor which indicates whether he is allowed to 
donate, updates blood group, and donor ID to the client application on the smartphone through the internet. It must be noted that the donor ID might not be the same as the person's ID during the registration. Each time a person donate blood, he is given a new donor id, which will be pasted on blood bag later. The status of the donor also includes the indication on whether the donor is allowed to proceed directly to bleeding room or he has to take certain light snacks beforehand. This situation occurs in situations where the donor has not eaten anything prior to donating but has a good medical condition.

The donor then proceeds to the bleeding room. The nurse checks the donor's status and prepare for extraction. Before blood is extracted, the nurse requests the donor to touch the phone to an NFC tag. The donor is then awarded with points to get reward if the extraction is successful. The starting time and expected finished time are then displayed on the phone screen. Encouraging messages are also displayed to reduce the anxiety of waiting. When the extraction is completed, the nurse will touch the phone to the reader again to transfer data to the system such as starting time, end time and duration.

\section{System Architecture}

The proposed system uses client and server architecture. The server processes and responses on requests and it manage the database as well. An application that runs on a smartphone will act as the client. The smartphone has to be equipped with a Near Field Communication (NFC) and $\mathrm{Wi}-\mathrm{Fi}$ adapters to communicate with the server. Fig 2 shows the proposed architecture of the system.

\section{Notification Broadcaster}

Besides improving the donor experience during blood donation, communication between NBC and donor can also be improved. As the current system send an SMS for notification, a more detailed and attractive notification can be sent to the donor's phone through the application with an internet connection. With internet, the broadcasting system will not incur additional charges. The notification can also contain rich information such as images, web addresses, locations and directions to campaign sites. This method of broadcasting advertisement is hoped to increase awareness and the number of donors.

To solve the data security issue during blood campaigns, the blood bank system can be designed so that it can be accessed using the internet. The client can access the server using a web browser or an installed application in order to be more secured. If the server can be reached by a web browser, the client can access it using a smartphone without the necessity of a laptop. If internet connection is unavailable, then data can be stored in the local drive temporarily.

As a summary, this research proposes four features which are shown in Table I.

TABLE I

FEATURES SUMMARY OF PROPOSED SYSTEM

\begin{tabular}{|l|l|l|}
\hline No. & $\begin{array}{l}\text { Feature of Proposed } \\
\text { System }\end{array}$ & Challenges \& Issues Solved \\
\hline 1. & $\begin{array}{l}\text { Registration using } \\
\text { NFC smartphone }\end{array}$ & $\begin{array}{l}\text { Avoid unreadable chip on identity } \\
\text { card }\end{array}$ \\
\hline 2. & $\begin{array}{l}\text { Notification } \\
\text { broadcaster }\end{array}$ & $\begin{array}{l}\text { Reduce SMS's cost and richer } \\
\text { content }\end{array}$ \\
\hline 3. & $\begin{array}{l}\text { Blood donation } \\
\text { assistance for donor }\end{array}$ & $\begin{array}{l}\text { Improve donor experience and } \\
\text { track donor's progress }\end{array}$ \\
\hline 4. & Points of reward & Motivates donor to return \\
\hline
\end{tabular}

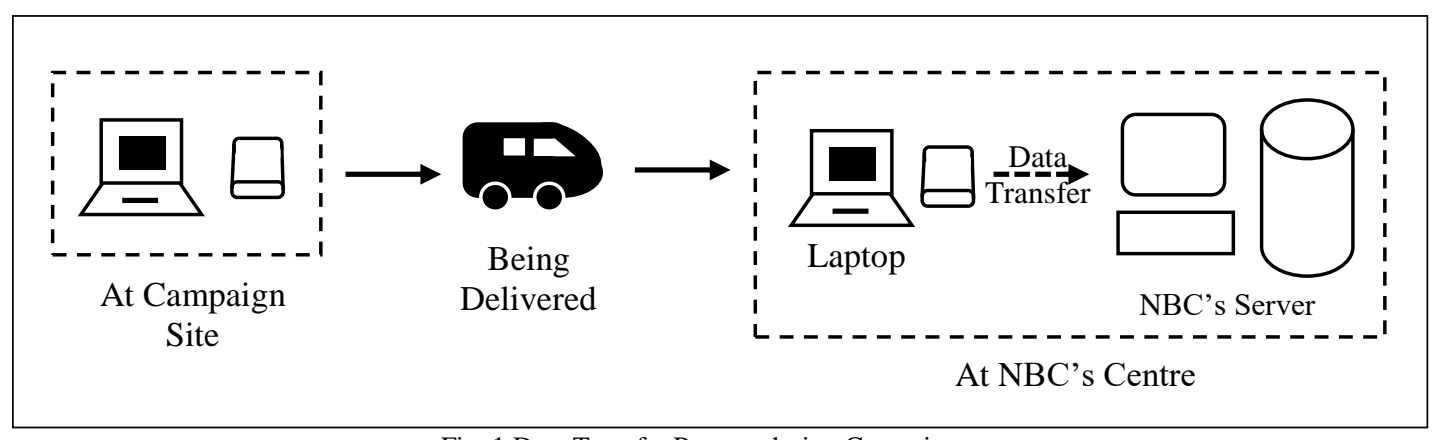

Fig. 1 Data Transfer Process during Campaign

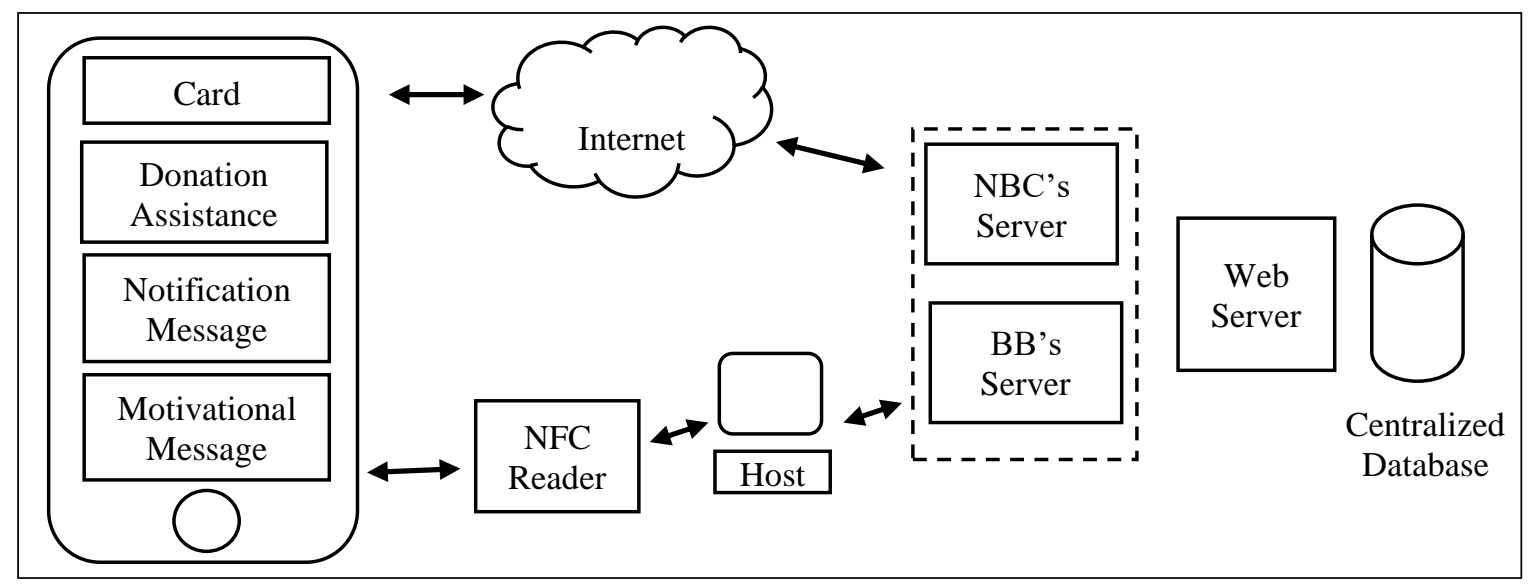

Fig 2. System Architecture Compliance with NFC 
[10] V. Hemmelmayr, K. F. Doerner, R. F. Hartl, and M. W. P.

\section{CONCLUSION AND FUTURE WORK}

Challenges and issues of NBC have been presented in this paper. Not every issue faced by NBC can be solved with the proposed system. However, the proposed system is expected to have better engagement with the donors, broaden the donor's experience and motivate donors to return.

It is difficult to avoid the negative effects after donation, be it psychologically or physically [42]. However, it is hoped that through the proposed system, NBC has a better approach to the donor with the purpose of reducing negative and increasing positive effect. To test whether the proposed system have a better engagement and a more positive impact to a donor, further studies have to be conducted.

NFC requires a phone to be close enough with a reader. This means that the donors have to touch the reader themselves or by the help of nurses. It is understandable that donors might not be comfortable if requested to pass the phone a few times during the process of donation. There are at least reasons that can cause such reluctance. Firstly, the phone is a personal device which contains personal information. Secondly, a smartphone is a multifunction device which allows the user to perform various tasks such as messaging, playing games, scheduling an appointment, etc. Therefore, to reduce the inconvenience especially during the blood extraction, donors are offered with points. The points can then be collected to obtain rewards.

Although more people are using smartphones [43], the possibility of owning only a basic phone cannot be discounted. A basic phone is only able to receive notifications through SMS. Therefore, the upcoming architecture design must consider the two ways of notification.

\section{ACKNOWLEDGMENT}

This project is funded by the grant: FRGS/2/2014/ICT01/UKM/02/1. We also express our gratitude to $\mathrm{NBC}$, which has permitted to conduct the case study and facilitated the data gathering.

\section{REFERENCES}

J. C. Faber, "Blood cold chain," ISBT Sci. Ser., vol. 2, no. 2, pp. 16, 2007.

[2] N. Guo et al., "Demographics of apheresis platelet donors in five blood centers in China," Transfusion, vol. 52, no. 3, pp. 560-566, 2012.

[3] A. R. Cross, "Whole Blood and Red Blood Cells," 2014. [Online] Available: http://www.redcrossblood.org/learn-about-blood/bloodcomponents/whole-blood-and-red-blood-cells. [Accessed: 01-Oct2014].

[4] A. R. Cross, "Plasma," 2014. [Online]. Available: http://www.redcrossblood.org/learn-about-blood/bloodcomponents/plasma. [Accessed: 01-Oct-2014].

[5] Pusat Darah Negara, "Pusat Darah Negara," 2014. [Online]. Available: http://www.pdn.gov.my/. [Accessed: 01-Oct-2014].

[6] J. Beliën and H. Forcé, "Supply chain management of blood products: A literature review," European Journal of Operational Research, vol. 217. pp. 1-16, 2012.

[7] World Health Organization, "Blood safety and availability," 2017 [Online]. Available:

http://www.who.int/mediacentre/factsheets/fs279/en/. [Accessed: 19-Feb-2018].

[8] World Health Organization, "Developing a National Blood System for Ministries of Health," 2011.

[9] W. P. Pierskalla, "Supply Chain Management of Blood Banks," in Operations Research and Health Care, vol. 70, 2005, pp. 103-145.
Savelsbergh, "Delivery strategies for blood products supplies," $O R$ Spectr., vol. 31, no. 4, pp. 707-725, Mar. 2008.

[11] H. Javadzadeh Shahshahani, "Why don't women volunteer to give blood? A study of knowledge, attitude and practice of women about blood donation, Yazd, Iran, 2005.," Transfus. Med., vol. 17, no. 6, pp. 451-4, Dec. 2007.

[12] B. M. Masser, K. M. White, M. K. Hyde, and D. J. Terry, "The Psychology of Blood Donation: Current Research and Future Directions," Transfus. Med. Rev., vol. 22, pp. 215-233, 2008.

[13] R. Bekkers and P. Wiepking, "A literature review of empirical studies of philanthropy: Eight mechanisms that drive charitable giving," Nonprofit Volunt. Sect. Q., vol. 40, no. 5, pp. 924-973, 2010.

[14] T. C. Bednall and L. L. Bove, "Donating blood: A meta-analytic review of self-reported motivators and deterrents," Transfus. Med. Rev., vol. 25, no. 4, pp. 317-334, 2011.

[15] A. F. Eder, C. D. Hillyer, B. A. Dy, E. P. Notari, and R. J. Benjamin, "Adverse reactions to allogeneic whole blood donation by 16 - and 17-year-olds.," JAMA, vol. 299, no. 19, pp. 2279-2286, 2008.

[16] P. Tomasulo, H. Kamel, M. Bravo, R. C. James, and B. Custer, "Interventions to reduce the vasovagal reaction rate in young whole blood donors," Transfusion, vol. 51, no. 7, pp. 1511-1521, 2011.

[17] E. Karacan, G. Cengiz, Z. Aktan, M. Ayli, and R. Palabiyikoglu, "Transfusion and Apheresis Science Blood donors and factors impacting the blood donation decision : Motives for donating blood in Turkish sample," Transfus. Apher. Sci., 2013.

[18] C. Mellström and M. Johannesson, "Crowding out in blood donation: Was Titmuss right?," J. Eur. Econ. Assoc., vol. 6, no. 4 pp. 845-863, 2008.

[19] A. H. Misje, V. Bosnes, and H. E. Heier, "Gender differences in presentation rates, deferrals and return behaviour among Norwegian blood donors," Vox Sang., vol. 98, 2010.

[20] B. N. Sojka and P. Sojka, "The blood donation experience: Selfreported motives and obstacles for donating blood," Vox Sang., vol. 94, pp. 56-63, 2008.

[21] L. P. Choudhury and S. Tetali, "Ethical challenges in voluntary blood donation in Kerala, India.," J. Med. Ethics, vol. 33, no. 3, pp. 140-2, Mar. 2007.

[22] T. Roshan and H. Rosline, "Response rate of Malaysian blood donors with reactive screening test to transfusion medicine unit calls," ... Asian J. ..., vol. 40, no. 6, p. 1315, 2009.

[23] A. M. Ngoma, A. Goto, Y. Sawamura, K. E. Nollet, H. Ohto, and S. Yasumura, "Analysis of blood donor deferral in Japan: characteristics and reasons.," Transfus. Apher. Sci., vol. 49, no. 3, pp. 655-60, Dec. 2013.

[24] S. Zou, F. Musavi, E. P. Notari, J. A. Rios, J. Trouern-Trend, and C. T. Fang, "Donor deferral and resulting donor loss at the American Red Cross Blood Services, 2001 through 2006," Transfusion, vol. 48, pp. 2531-2539, 2008.

[25] T. T. Gonçalez et al., "Analysis of donor deferral at three blood centers in Brazil," Transfusion, vol. 53, pp. 531-538, 2013.

[26] N. Vavic, A. Pagliariccio, M. Bulajic, R. Dinić, and M. Marinozzi, "Giving blood donors something to drink before donation can prevent fainting symptoms: is there a physiological or psychological reason?," Transfus. Apher. Sci., Jul. 2014.

[27] T. C. Bednall, L. L. Bove, A. Cheetham, and A. L. Murray, "A systematic review and meta-analysis of antecedents of blood donation behavior and intentions," Social Science and Medicine, vol. 96. pp. 86-94, 2013.

[28] Pusat Darah Negara, "Sejarah," 2015. [Online]. Available: http://pdn.gov.my/pdn/index.php?option=com_content\&view=articl e\&id=72\&Itemid=147\&lang=en. [Accessed: 12-Jan-2015]. 2006.

Pusat Darah Negara, "Perolehan Darah,” 2015. [Online]. Available: http://www.pdn.gov.my/pdn/index.php?option=com_content\&view $=$ article \&id=76\&Itemid=153\&lang=en. [Accessed: 04-May-2015]. Pusat Darah Negara, "Pembekalan," 2015. [Online]. Available: http://www.pdn.gov.my/pdn/index.php?option=com_content\&view =article\&id=79\&Itemid=156\&lang=en. [Accessed: 04-May-2015]. Pusat Darah Negara, "Waktu Operasi," 2015. [Online]. Available: http://pdn.gov.my/pdn/index.php?option=com_content\&view=articl e\&id=101\&Itemid=179\&lang=en. [Accessed: 05-May-2015].
B. N. Li, S. Chao, and M. C. Dong, "Barcode Technology in Blood Bank Information Systems: Upgrade and Its Impact," J. Med. Syst., 
vol. 30 , no. 6 , pp. $449-457$, Nov. 2006

[34] R. W. Askeland, S. P. McGrane, D. R. Reifert, and J. D. Kemp, "Enhancing transfusion safety with an innovative bar-code-based tracking system.," Healthc. Q., vol. 12, pp. 85-89, 2008.

[35] K. Ralf et al., "Guidelines for the Use of RFID Technology in Transfusion Medicine,” Vox Sang., vol. 98, no. April, pp. 1-24, Apr. 2010.

[36] M. Attaran, "RFID: an enabler of supply chain operations," Supply Chain Manag. An Int. J., vol. 12, no. 4, pp. 249-257, 2007.

[37] A. Gutierrez et al., "Tracking blood products in hospitals using radio frequency identification: Lessons from a pilot implementation," ISBT Sci. Ser., vol. 8, pp. 65-69, 2013.

[38] Ministry of Health Malaysia, “Transfusion Practice Guidelines for Clinical and Laboratory Personnel," 2008.

[39] R. Want, "An introduction to RFID technology," Pervasive Comput. IEEE, vol. 5, no. 1, pp. 25-33, 2006
[40] Z. Antoniou and S. Varadan, "iTouch: RFID middleware for boosting connectivity and intuitive user interaction in smart spaces," 2006

[41] B. Ozdenizci, M. N. Aydin, V. Coskun, and K. Ok, "NFC Research Framework: A Literature Review And Future Research Directions," 2010, pp. 23-24

[42] B. N. Sojka and P. Sojka, "The blood-donation experience: Perceived physical, psychological and social impact of blood donation on the donor," Vox Sang., vol. 84, pp. 120-128, 2003.

[43] M. Tsai, "The trends for smartphone products and software consumption in Taiwan: An application research combining industry analysis and consumer focus group interviews," in Technology Management in the IT-Driven Services (PICMET), 2013 Proceedings of PICMET '13:, 2013, pp. 2338-2343. 